\section{Literature Cited}

Akersten, W. A. 1985. Canine function in Smilodon (Mammalia, Felidae, Machairodontinae). Natural History Museum of Los Angeles County, Contributions in Science 356:1-22.

Cope, E. D. 1880. On the extinct cats of America. American Naturalist 14:854-858.

DeSantis, L. R. G., ET AL. 2019. Causes and consequences of Pleistocene megafaunal extinctions as revealed from Rancho La Brea mammals. Current Biology 29:2488-2495.

Fuller, B. T., J. M. Harris, A. B. Farrell, G. T. TAKeuchi, AND J. R. Southon. 2015. Sample preparation for radiocarbon dating and isotopic analysis of bone from Rancho La Brea. Pp. 151-168 in La Brea and beyond: the paleontology of asphalt-preserved biotas (J. M. Harris, ed.). Natural History Museum of Los Angeles County, Science Series, Los Angeles, California, USA. Vol. 42.

Lindsey, E. L., AND K. L. Seymour. 2015. "Tar Pits” of the western neotropics: paleoecology, taphonomy, and mammalian biogeography. Pp. 111-123 in La Brea and beyond: the paleontology of asphalt-preserved biotas (J. M. Harris, ed.). Natural History Museum of Los Angeles County, Science Series, Los Angeles, California, USA. Vol. 42.

Merriam, J., And C. Stock. 1932. The Felidae of Rancho La Brea. Carnegie Institute of Washington Publications 442:1-231.

Naples, V. L., L. D. Martin, and J. P. Babiarz (eds.). 2011. The other saber-tooths: scimitar-tooth cats of the Western Hemisphere. Johns Hopkins University Press, Baltimore, Maryland.

PAIJMANS, J. L. A., ET AL. 2017. Evolutionary history of saber-toothed cats based on ancient mitogenomics. Current Biology 27:3330-3336.e5.

Woodard, G. D., And L. F. Marcus. 1973. Rancho La Brea fossil deposits: a re-evaluation from stratigraphic and geologic evidence. Journal of Paleontology 47:54-69.

DOI:10.1093/jmammal/gyz154 Published online October 21, 2019

\section{Everything you always wanted to know about sexual selection in 129 pages}

Zuk, M., and L. W. Simmons. 2018. SeXual Selection: A Very Short Introduction. Oxford University Press, New York. ISBN: 978-0-19-877875-2, 2005 pp (paperback). \$11.95.

(C) 2019 American Society of Mammalogists, www.mammalogy.org

"Very short introductions" are portable paperbacks, aimed at explaining one topic to a general audience. In slightly more than 100 pages, they introduce the curious reader to the "greatest hits" (Yahnke 2018) of a particular topic in science, history, philosophy, art, etc. A recent addition to this series is "Sexual selection: a very short introduction," by Marlene Zuk and Leigh Simmons. In eight short chapters, Zuk and Simmons describe the history and central ideas of sexual selection. The book also includes recent and future developments in the field.
Chapter 1, titled "Darwin's other big idea," provides a good incipit, featuring practical examples of sexual dimorphism across species. It describes how, historically, sexual selection has always been more controversial than natural selection, Darwin's "main idea." Zuk and Simmons mention how Darwin was only one of several intellectuals developing the idea of sexual selection. The chapter stresses the difficulties faced by those scientists in the past working on sexual selection: The field had to deal with philosophical dogmas contrary to extending sexual selection to human mate choice, and cross fire from critiques of eugenics. The chapter also recounts the Victorian's prejudices about animal perceptual capacities. Finally, the chapter highlights the link between sexual selection and one big conceptual step in the 1960s, namely moving from species-centrism to the study of individual preferences.

Chapter 2, "Mating systems, or who goes with whom, and for how long," mixes science and anecdote while describing the immense variability in animal mating systems. It features a section on the rarity of monogamy in mammals, and another on the aggregative phenomenon of leks. This chapter stresses the importance of avoiding grand generalizations and conceptual shortcuts, and outlines the potential practical applications of studying mating systems, such as how to best conserve populations.

Chapter 3, "Choosing from the field of competitors," focuses on mate choice, and feels weightier than all the other chapters. This chapter introduces the idea of sensory biases (see also Ryan 2019) as a potential mechanism for mate choice. This chapter provides examples of female choice based on genetic compatibility, including in humans (e.g., the major histocompatibility complex). This chapter also describes some research in human mate choice from biological anthropology.

Chapter 4, "Sex roles and stereotypes," showcases the large variability in sex roles across species. This chapter features several mammalian examples: chimpanzees and bonobos, but also "sneaky" elephant seals. In this pinniped species, for instance, the largest males copulate with the greatest number of females, but smaller males remain inconspicuous and can sneak up to some females to copulate.

Chapter 5, "Sexual selection after mating," explores the facets of sexual selection once copulation is over, for example, in the form of sperm competition. This chapter also provides several mammalian examples. This chapter discusses how body size and testes size correlate across primates; however, in outlier primate species, where females mate with multiple males, male testes are larger than normal. This chapter presents an amusing case of "suicide by sperm production" whereby males of the Australian marsupial Antechinus invest so many resources on sperm production to the point that their immune system collapses and they die. Finally, this chapter introduces the reader to the baculum which is absent in humans and shows extreme cross-species diversity.

Chapter 6, "Sexual conflict," discusses the cost and benefits of sex for females and males. It features several uncommon examples. This chapter discusses chase-away sexual selection, leading to a decrease of female preference for a male-selected trait. This decrease stands in contrast with the more common increase of female preference seen in Fisherian runaway 
selection. Chapter 6 links to Chapter 3 and features another example of cross-species sensory exploitation. As a defense mechanism, moths become immobile upon hearing a specific bat call. Male moths have evolved to produce a bat-like sound so that, once a female is immobilized by the sound, they can freely mate with her. This chapter concludes with a discussion on sexually antagonistic co-evolution, and a plea for research in more species to understand how widespread sexual conflict is.

Chapter 7, "How sex makes species survive," focuses on the potential relationship between sexual selection and speciation, which could be linked via genetic or physical incompatibility. While this chapter mostly focuses on nonmammalian species, it does mention assortative mating in humans, whose study is however difficult because potentially confounded by other factors, such as socioeconomic status. This chapter also devotes a section to the role of behavior in speciation, which is controversial but likely.

Chapter 8, "Conclusions, and where to from here," acknowledges that sex is a delicate topic, which can stir arguments and result in polarization. The argument is made that animals are variable in sexual behavior, and they should not constitute a model for human sexual behavior. To understand the dynamics of sexual selection, one must compare many species. This chapter describes several recently developing areas in sexual selection and evolutionary biology. Epigenetics is one of these areas, also discussed in detail in a recent, intriguing popular book (Bonduriansky and Day 2018).

To conclude, Zuk and Simmons' book is enjoyable and informative. The book sometimes feels a bit academic, slightly more so than the typical very short introduction. Notably, the book features several "What about us?" (i.e., humans) sections, which are a good narrative device to engage the reader by relating biological themes to human everyday life. Apart from humans, however, other mammals are not often featured. One explanation for this is indirectly offered by the authors when discussing sexual selection on animal signaling. Many nonmammalian species use one single type of sexual signal to choose partners, making them easier to study. While not featuring many mammals, the book instead offers ideas and concepts from other species which a mammalogist will be able to relate to mammals.

-Andrea Ravignani, ${ }^{\circ}$ Research Department, Sealcentre Pieterburen, Hoofdstraat 94a, 9968 AG Pieterburen, The Netherlands \& Artificial Intelligence Lab, Vrije Universiteit Brussel, Pleinlaan 2, 1050 Brussels, Belgium; e-mail: andrea. ravignani@gmail.com.

\section{Literature Cited}

Bonduriansky, R., AND T. DAy. 2018. Extended heredity: a new understanding of inheritance and evolution. Princeton University Press, Princeton, New Jersey.

RYAN, M. 2019. A taste for the beautiful: the evolution of attraction. Princeton University Press, Princeton, New Jersey.

YAHNKE, C. J. 2018. Mammals: a very short introduction. Journal of Mammalogy 99:1271-1272.

DOI:10.1093/jmammal/gyz168

\section{Mammals of Korea}

\author{
Yeong-Seok Jo, John T. Baccus, and John L. Koprowski. \\ 2018. Mammals of Korea. Life Science Publishing Co., Seoul, \\ Korea, 2007 pp. ISBN: 978-89-6811-369-7 (hard cover), \$ free. \\ (C) 2019 American Society of Mammalogists, www.mammalogy.org
}

The book Mammals of Korea by Yeong-Seok Jo, John T. Baccus, and John L. Koprowski is a much-needed, user-friendly, and well-written detailed guide to Korean mammals. All species are beautifully illustrated by Yo-Han Ji, giving the reader a visually delightful experience. It is hard to find criticisms to this hard copy, large-size, 573-page long book. With an easy-to-use index at the front and Orders marked in colors in the fore-edge, it makes the experience easy for readers who want to explore and get to know better the mammals of Korea in a simple and straightforward way.

The authors address concisely and clearly this work through a very detailed initial content section (six chapters) with a first chapter on an introduction to the Korean Peninsula. Rightly so, the complex political history of the Korean Peninsula, and current division at the Demilitarized Zone (DMZ) between the North (Democratic People's Republic of Korea - North Korea) and the South (Republic of Korea - South Korea), begs for such a chapter. The following chapters address the overall history of the peninsula, mammal hotspots and biodiversity, history of Korean mammalogy, conservation, fossil mammals and zoogeography, and species accounts.

The authors report on erroneous identifications of eight species and identify a total of 127 species that are or were once present in the peninsula, 84 of which are terrestrial and 43 marine mammals, distributed in eight orders and 32 families. Unlike some species atlases, which only illustrate species' distribution maps within the area of interest, this book shows the species ranges in Korea, but also outside Korean borders, including Japan. The overall species ranges gives the reader a much broader understanding of the mammal biodiversity of Korea and surrounding countries and is key to appreciating the likely role of the peninsula from a biogeographic perspective.

Overall, this book is of importance for a number of reasons. From a biogeographic perspective, the Korean Peninsula is unique as it is peripheral to some widely distributed Eurasian species, and its mammalian fauna, as well as in its surrounding Pacific islands, still remain poorly studied. In addition, the dissemination of information and species taxonomy has mostly been published in Korean or Japanese, restricting scholars from abroad to material on Korean mammals. Similarly, the division of the peninsula into North and South has obstructed the divulgation of knowledge throughout with lack of communication between both sides. Furthermore, long wars, anthropogenic impact on habitats, mostly through agriculture, have had profound consequences to the local mammal biodiversity, with the loss of numerous large mammal species.

This work is both educational and entertaining, being sufficiently documented to meet the needs of professionals but 